ISSN 2236-0859

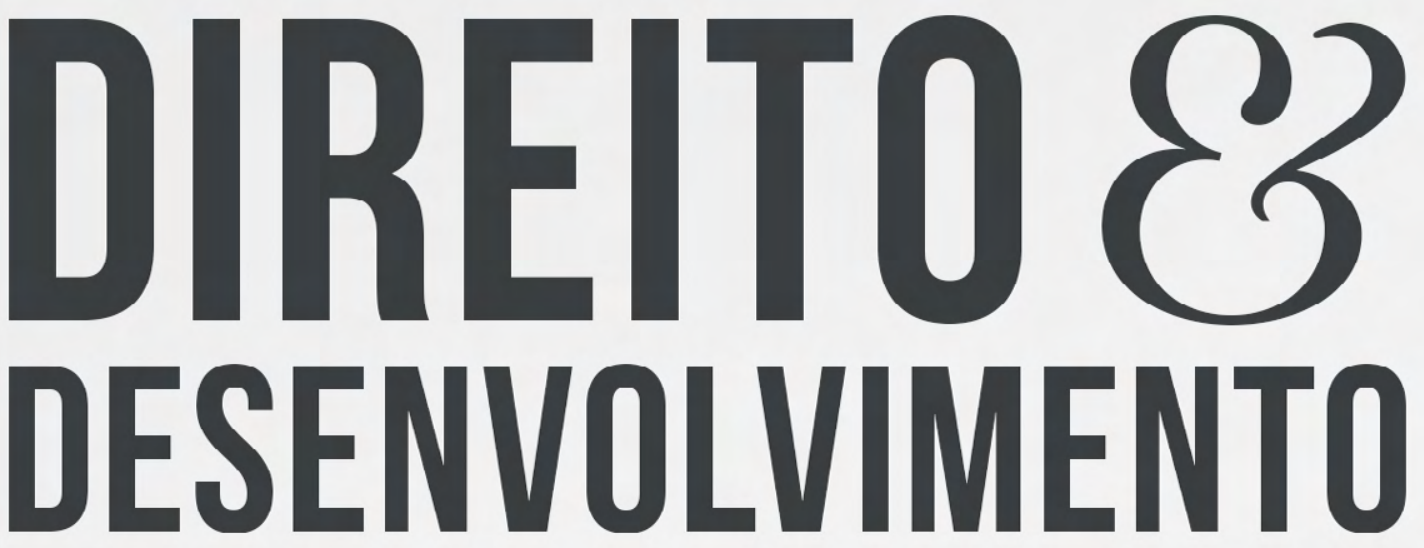

REVISTA DO PROGRAMA DE PÓS-GRADUAÇÃO EM DIREITO MESTRADO EM DIREITO E DESENVOLVIMENTO SUSTENTÁVEL

DESENVOLVIMENTO ECONÔMICO SUSTENTÁVEL EAS EXTERNALIDADES AMBENTAIS

REGINA CÉLIA CARVALHO DE MARTINS MARISA ROSSIGNOLI 


\title{
DESENVOLVIMENTO ECONÔMICO SUSTENTÁVEL E AS EXTERNALIDADES AMBIENTAIS
}

\section{SUSTAINABLE ECONOMIC DEVELOPMENT AND ENVIRONMENTAL EXTERNALITIES}

Recebido: 19/12/2017

Aprovado: 01/10/2018

\author{
Regina Célia Carvalho de Martins* \\ Marisa Rossignoli**
}

RESUMO: O presente estudo objetiva a discussão conceitual das externalidades no que se refere à questão ambiental, embasado nos novos paradigmas da sustentabilidade que ela deve respeitar. É elaborado por meio de revisão bibliográfica nos autores que tratam de externalidades negativas, direito ambiental e desenvolvimento econômico sustentável e análise do texto da Constituição Federal, principalmente dos preceitos apresentados no artigo 170 que permeiam o desenvolvimento econômico que atenda a diversos critérios, entre eles a necessidade de preservar o meio ambiente. Apresenta-se assim como problema de pesquisa central a atuação do Estado no que se refere à regulação das externalidades empresariais. A pesquisa é de caráter exploratório. Verifica-se que a exigência de desenvolvimento sustentável que se busca com preservação e recuperação de bens ambientais degradados exige que o Estado atue regulando as atividades empresariais, quando estas atingem o meio ambiente em seus processos produtivos, criando normas que determinem à empresa a internalização dos custos que as externalidades ambientais ocasionam; assim, com este complexo de atuação que engloba empresas, sociedade e Estado, busca-se cumprir as metas de desenvolvimento econômico sustentável desejável para a preservação do meio ambiente e da vida saudável.

Palavras chave: Desenvolvimento sustentável. Externalidades. Função social da empresa. Regulação.

\begin{abstract}
This study aims at the conceptual discussion of externalities with regard to the environmental issue. The article is elaborated through a bibliographical review focused on authors dealing with negative externalities, environmental law and sustainable economic development and analysis of the text of the Federal Constitution, mainly the precepts presented in article 170 that permeate the economic development that meets several criteria, among them the need to preserve the environment. Thus, as a central research problem, the State's performance regarding the regulation of corporate externalities. The research is exploratory. It is verified that the requirement for sustainable development that seeks to preserve and recover degraded environmental goods requires the State to regulate business activities, when they reach the environment in their production processes, creating norms that determine the company to internalize the costs that environmental externalities cause; thus, with this complex of action that encompasses companies, society and the State is sought to fulfill the goals of sustainable economic development desirable for the preservation of the environment and healthy life.
\end{abstract}

Keywords: Sustainable development. Externalities. Company’s social function. Regulation.

\footnotetext{
* Professora de Direito Civil e Direito Ambiental da Universidade de Marília - UNIMAR. Mestre em Direito pela UNIMAR-SP. Doutoranda em Direito - UNIMAR-SP. Presidente da Comissão de Meio ambiente da 31로 subsecção da OAB/SP. E-mail: martinsre31@hotmail.com. ** Economista pela UNESP- Araraquara. Mestre em Economia pela PUC-SP. Doutora em Educação (Política e Gestão) pela Universidade Metodista de Piracicaba - UNIMEP; Professora da área de Economia do Mestrado e Doutorado em Direito da UNIMAR.Delegada Municipal do CORECON SP - Conselho Regional de Economia de São Paulo para o Município de Marília - SP. E-mail: mrossignoli@unimar.br.
} 


\section{INTRODUÇÃO}

Desenvolvimento econômico sustentável é um dos maiores desafios para as sociedades contemporâneas. A visão histórica de desenvolvimento calcada na inerente necessidade humana de reduzir desigualdades e promover a justiça distributiva, melhorando as condições sociais dos indivíduos, por certo deve observar que o desenvolvimento das atividades da humanidade afeta o meio ambiente e leva a necessidade de reavaliar tais conceitos.

Desde os primórdios até o homem moderno, o ser humano interage com o meio ambiente e retira da natureza todos os recursos que julga necessários para atender suas necessidades e prazeres.

Alguns pensadores, como é o caso de Schumpeter (1997) comungam do entendimento de que existe uma teoria destruidora, afirmando que para o surgimento de uma inovação, outro bem deve ser destruído. Trazendo esse paradigma para os bens ambientais que são transacionados verifica-se que a escassez de um bem resulta em aumento de seus preços, impulsionando a criação de novas tecnologias com o fito de poupar esses recursos que se escasseiam.

Pode-se observar com o decurso do tempo e o crescimento econômico, que as sociedades reagem de forma pronta em relação a esta escassez, já que acabam sofrendo com a poluição crescente em razão da degradação ambiental, o que as faz voltar seu olhar para a necessidade de mudanças efetivas contra essa degradação; assim, é possível perceber que com o desenvolvimento econômico e cultural, ocorre uma mudança de paradigmas em relação ao meio ambiente e sua preservação.

A observação dos fatos históricos mostra que a intervenção humana no meio ambiente, trazendo externalidades negativas, data do surgimento da espécie humana no planeta; entretanto, os de preservação ambiental, no Brasil somente ganham maior intensidade após década de 1960, com uma fase de intenso movimento migratório das lides do campo para as áreas urbanas. Foi a crise do petróleo, ocorrida no final dos anos sessenta e início da década de setenta que demandou uma reflexão mais efetiva sobre o futuro da humanidade em relação ao meio ambiente.

É neste contexto que surge o conceito de desenvolvimento sustentável como um termo que expressa os anseios coletivos, tais como a democracia e a liberdade, momento em que se aprofundam os estudos sobre as externalidades negativas da ação humana sobre o meio ambiente.

Em todo o cenário apresentado, pode-se compreender que a empresa desempenha importante papel, sendo preciso equalizar as finalidades a que ela se propõe; se por um lado ela deve proporcionar desenvolvimento econômico, por outro lado para que ela venha a promovê-lo de modo eficiente e sustentável, deve se preocupar de forma integrativa, com as externalidades negativas ambientais que ocasiona, as quais devem ser consideradas em seus custos operacionais, de modo a desenvolver atividades empresariais e contribuir para a preservação ambiental.

Assim, com o uso da revisão bibliográfica, o presente artigo busca a discussão conceitual das externalidades no que se refere à questão ambiental, bem como dos conceitos de desenvolvimento e sustentabilidade, para, na sequência, analisar a questão dos investimentos empresarias frente a estas questões e discutir o problema da regulação para que as externalidades não tenham um custo para a sociedade e sim sejam internalizadas nos custos empresariais. $\mathrm{O}$ método de pesquisa utilizado é o dedutivo. 


\section{EXTERNALIDADES E EXTERNALIDADES AMBIENTAIS}

A preocupação com o meio ambiente que deu origem à noção de sustentabilidade demonstra que a não observação da sustentabilidade ambiental tende a limitar o crescimento econômico em geral. A exaustão de determinados insumos ambientais, gera a elevação dos preços e restringe o uso dos mesmos, o que não acontece no caso dos serviços ambientais, cujo mercado não sinaliza a escassez; surgindo então o conceito de externalidade.

As externalidades são as falhas de mercado que alcançam grande importância no estudo dos recursos naturais e na economia ambiental. Desta forma se reconhece que o mercado pode não funcionar de modo eficiente, perfeito, ótimo, para com isso organizar a economia, apresentando falhas (BAGNOLI, 2008).

Externalidades são "falhas de mercado nas quais efeitos de determinada atividade atingem terceiros (externos) nela não envolvidos” (DERANI, 2007, p.57).

Dentro de um processo produtivo as externalidades ambientais surgem no momento em que o setor produtivo se utiliza do meio ambiente e seus recursos de forma gratuita. $\mathrm{O}$ setor produtivo deveria pagar pelo uso dos bens de ambientais ou mesmo pela poluição destes recursos naturais; entretanto, a inexistência de meios legais para a cobrança ou punição, faz com que os recursos naturais sejam utilizados, muitas vezes, de forma indevida e irresponsável.

Motta (1997) defende que a utilização dos bens ambientais deve gerar uma contribuição e um bem estar social:

Bens públicos e externalidades: na qual analisam se as imperfeições do mercado em definir apropriadamente os direitos de propriedade que determinam o padrão de uso e distribuição dos recursos e sua contribuição para o bem estar social (MOTTA, 1997, p. 197).

Com estas avaliações percebe-se que a utilização das águas e do ar atmosférico por uma indústria, por exemplo, pode gerar externalidades negativas. A indústria não tem custo por liberar fumaça e poluir o ar e não paga também por despejar dejetos nas águas dos rios. Tais comportamentos podem ocasionar mortandade de peixes, ou chuvas ácidas, que são externalidades negativas à produção e que devem ser consideradas quando se pensa em preservação ambiental.

As externalidades podem ser positivas ou negativas. As externalidades positivas são consideradas benéficas e se consubstanciam na atuação de um agente, que externaliza benefícios para terceiros sem que esses paguem pelos benefícios recebidos, podendo se citar como exemplo a geração de empregos e maior circulação de recursos econômicos em uma localidade onde se instala uma fábrica. Já externalidades negativas ocorrem quando as decisões de produção e de consumo afetam a disponibilidade dos serviços e reduzem o bem-estar ou a produção de outros. A mesma fábrica sobredita, por exemplo, polui o rio local por falta de legislação ambiental que a proíba de agir assim.

As externalidades não estão relacionadas a um comportamento bondoso ou malicioso das empresas que geram estes efeitos, mas por vezes é fruto de uma dificuldade de se policiar o uso de recursos. Ademais, as externalidades são involuntárias, ou seja, não são previamente planejadas. A poluição atmosférica do exemplo acima é um caso; trata-se de uma consequência da atividade industrial desenvolvida, que ocasiona efeitos nocivos a terceiros.

Observando-se por outro ângulo é possível se dizer que ocorre um enriquecimento do empreendedor à custa de um efeito negativo suportado pela sociedade, já que no custo deste 
produto não se incluiu o desgaste suportado pela sociedade. Pode-se dizer que ocorre uma privatização de lucros (empresa) e socialização de perdas (sociedade).

"Neste sentido, o papel do Estado e a participação social são de fundamental importância para que haja a internalização dos custos pelas empresas e o desenvolvimento econômico de forma sustentável" (ROLIM et al., 2014, p. 63-67).

Não obstante, o debate sobre o real papel do Estado tem se estendido pela análise econômica do Direito. Tal debate pode ser resumido pelas visões de Pigou (1920) e Coase (1960).

Na teoria econômica Pigou (1920, p. 20-22) "defende que o Estado deveria intervir definindo uma tributação que compensasse a externalidade negativa e garantisse o bem estar social." O Estado deveria agir de forma repressiva, por meio da tributação e responsabilização, mas deveria também estimular a redução das externalidades por meio de incentivos.

$\mathrm{O}$ referido autor trabalha com o conceito de custo marginal; assim, deveria ser mensurada a diferença entre o custo marginal privado e social.

Pigou (1920) utiliza o exemplo de uma fábrica, nesta atividade poluidora garante o lucro a um grupo de empresários, mas há externalidades negativas à sociedade. Assim, as mercadorias produzidas por estas empresas deveriam ser tributadas, elevando os preços para compensar a sociedade.

Com elevação da tributação e correspondente elevação do preço ocorreria queda na demanda. Caberia às empresas buscarem formas diferentes de produzir para que não fossem taxadas. Importante observar que neste processo há necessidade de um conhecimento pleno por parte do Estado sobre as atividades realizadas pelas empresas.

Por outro lado, Ronald Coase (1960) entende que as externalidades devem ser analisadas de forma bilateral. Devendo ser a regra na solução dos problemas a adoção pela opção que causasse menor prejuízo, devendo haver uma negociação entre as partes, e não a intervenção estatal direta.

O mercado se autorregularia, quando não houvesse a autoregulação em função dos custos de transação o Estado interferiria.

Importante destacar que é necessário que as externalidades negativas passem a ser computadas no custo de produção, ou seja, o custo social da externalidade deve ser levado em conta pelo agente na decisão de produção, bem como deve ser computada e utilizada como forma de responsabilizar os geradores dessas externalidades pelos danos ao meio ambiente.

Externalidades negativas devem ser internalizadas, ou seja, seu custo deve ser pago por quem as produz e não podem gerar consequências para terceiros; atividades potencialmente poluidoras devem internalizar para o empreendedor a responsabilidade pelas externalidades negativas.

Cabe ao produtor fomentar as práticas necessárias à diminuição, eliminação ou neutralização do dano ambiental e não à sociedade continuar arcando com os custos negativos dessa poluição.

Padilha (2010) ao se referir às falhas do mercado econômico apresenta que as externalidades negativas deveriam ser suportadas, pelo empreendedor, como consequência do princípio do poluidor pagador e não pela sociedade, que está alheia a este processo econômico.

A produção de resíduos é decorrência das falhas do mercado econômico. Tais falhas são denominadas "externalidades", pois geram prejuízos suportados por terceiros, alheios ao processo econômico, em decorrência do uso de determinados recursos naturais. Nesse sentido, o objetivo do princípio do poluidor pagador significa promover a "internalização" do custo ambiental, transformando a externalidade negativa, ou o custo social, num custo privado, pois não é possível admitir-se a socialização do prejuízo e a privatização dos lucros (PADILHA, 2010, p. 257). 
As externalidades negativas em matéria ambiental são danos gerados a terceiros e que precisam ser contabilizados para que seja possível se cumprir o princípio ambiental da reparação integral. A relação entre as externalidades negativas e este princípio ocorre quando se observa que externalidades negativas são causadoras de danos ambientais, que não sendo contabilizados ou suportados por seus geradores criam uma desproporção e imputam à sociedade sofrer estes danos, os quais deveriam ser suportados por aquele que se beneficia da atividade ambientalmente impactante.

Isso contraria o princípio da reparação integral do dano ambiental o qual dispõe que todo o dano ambiental deve ser suportado por quem o ocasionou e reparado, exigindo que a reparação seja integral.

Como visto até agora, a doutrina vem reiterando o entendimento da necessidade de ser sedimentada a nova ordem econômica social, criando novos paradigmas empresarias quanto à geração de externalidades ambientais, situação está presente na Constituição Federal em seu artigo 170, em que se pode constatar ter ocorrido sensível preocupação do legislador constitucional com os três pilares básicos do desenvolvimento sustentável que são: a) eficiência econômica; b) justiça social e c) preservação do meio ambiente.

Assim, as atividades de produção devem passar a entronizar essa nova visão de desenvolvimento econômico, em que os lucros da atividade empresarial devem ser balizados e computar também o uso de recursos naturais, verificando-se as perdas geradas por degradação ou exaustão de recursos naturais, fatores que precisam ser contabilizados, ou seja, a empresa deve deixar de externalizar os danos para a sociedade e o meio ambiente, internalizando-se estes à atividade empresarial.

Por isso, é importante que o governo atue para regular e fiscalizar a ocorrências das externalidades ambientais, introduzindo custos dela no sistema de preços ou criando mecanismos para sua redução.

O surgimento da legislação ambiental e a necessidade das empresas em cumpri-las é um fator que veio corroborar com estas necessidades do meio ambiente e faz com que o custo ambiental seja inserido nas atividades empresariais; assim, para se adaptar às normas ambientais e a nova exigência de sociedade, que hoje clama por empresas ambientalmente responsáveis, paulatinamente as empresas vêm realizando este processo de internalização de externalidades negativas.

A Constituição de 1988 tem papel fundamental nesta mudança de paradigmas empresariais, porque é por meio dela que se efetivou a nova visão econômica buscada pelo legislador constituinte. A empresa hoje deve pautar seu alicerce na sustentabilidade; o desenvolvimento econômico deve inserir em seus custos operacionais as externalidades ambientais negativas e fomentar as positivas, isto porque é o único meio da empresa cumprir sua responsabilidade social ambiental. Tal objetivo necessita de políticas públicas eficientes e fiscalização pontual, para que se cumpram os pilares do desenvolvimento sustentável, capazes de promover a preservação e recuperação dos recursos naturais.

\section{DESENVOLVIMENTO SUSTENTÁVEL E SUSTENTABILIDADE}

Se faz de fundamental importância a discussão sobre o desenvolvimento, uma vez que seu conceito pressupõe uma melhoria da condição de vida da população como um todo, pressupõe a existência de desenvolvimento social.

A ideia de desenvolvimento surge em um contexto histórico como uma necessidade de mudança de paradigma para se reparar as desigualdades sociais que podem ser 
observadas desde as épocas das antigas, em que existiam as nações metropolitanas e periferia colonial, situação semelhante que persiste até hoje, que se verifica a discrepância entre as minorias ricas e a maioria ainda exausta e atrasada de trabalhadores pobres. $\mathrm{O}$ desenvolvimento é o termo empregado como a promessa de uma modernidade inclusiva, com mudanças estruturais neste sistema (SACHS, 2008, p. 38).

Desde Aristóteles economia e ética caminhavam interligadas por duas questões de fundo relativas ao problema da motivação humana e avaliação das conquistas sociais, mas as questões logísticas da economia fizeram com que, ao longo do tempo a questão de lucros fosse preponderante e a ética ficasse esquecida. Atualmente, a reaproximação de ambas, economia e ética, aliadas à política (SEN, 2010) é fundamental para realizar o efetivo anseio do desenvolvimento com redução de desigualdades sociais; qual seja, o desenvolvimento sustentável.

Assim, o crescimento acelerado da economia que se verifica na era moderna não pode ser confundido com desenvolvimento, na medida em que não propicie o aumento de empregos, não seja capaz de reduzir a pobreza e nem atenue desigualdades sociais. É preciso que ocorra equidade em termos operacionais, de forma a tornar mais inclusiva a participação dos mais fracos no sistema. O conceito de desenvolvimento sustentável e a sustentabilidade ambiental passa a integrar a dimensão do desenvolvimento e sustentabilidade social e neste campo, as externalidades negativas ambientais da produção não podem ser esquecidas como parte do custo operacional de produção.

O desenvolvimento só ocorre quando há uma redistribuição dos frutos do crescimento econômico e isto se dá de forma sustentada (SUNKEL, 2001).

No relatório denominado "Nosso Futuro Comum" desenvolvido pela Comissão de Brundtland ocorrida no processo preparatório para a Conferência das Nações Unidas - também chamada de Rio 92 surgiu efetivamente o termo desenvolvimento sustentável. Neste relatório está inserida uma das definições mais difundidas do conceito de desenvolvimento sustentável: "o desenvolvimento sustentável é aquele que atende às necessidades do presente sem comprometer as possibilidades de as gerações futuras atenderem suas próprias necessidades" (COMISSÃO MUNDIAL..., 1988, p. 46).

O relatório Brundland faz muito mais do que estabelecer o conceito de desenvolvimento sustentável, ele considera que as políticas ambientais e de desenvolvimento para cumprirem os requisitos da sustentabilidade devem incluir a preservação da paz, o crescimento, mas alterando a qualidade deste, bem como remediando os problemas da pobreza e satisfazendo necessidades sociais, abordando os problemas do crescimento populacional e de conservação e reforço da base de recursos naturais, reorientando a tecnologia e gerindo os riscos; assim, reconhece que é necessária a fusão do ambiente e da economia, alicerçados pelas bases governamentais na tomada de decisões.

O conceito de desenvolvimento sustentável deve assim atender a um duplo imperativo ético que integra a geração atual com as futuras gerações, obrigando-nos a trabalhar com noções diversas daquelas relacionadas com a economia tradicional, que observa somente o lucro como objetivo precípuo. Reconhece-se que é preciso buscar soluções que eliminem o crescimento selvagem obtido ao custo de elevadas externalidades negativas e exige estratégias para propiciar um crescimento benéfico tanto do ponto de vista social como ambiental.

Paffarini, et al. (2017) observa que hoje o conceito de desenvolvimento está totalmente integrado à questão da sustentabilidade, apresentando a impossibilidade de haver crescimento econômico em longo prazo sem progresso social e sem cuidado com o meio ambiente.

Sachs vai além do já dito neste trabalho e ao estudar o tema, propõe cinco pilares para se alcançar o desenvolvimento sustentável: 


\begin{abstract}
a) Social, fundamental por motivos tanto intrínsecos quantos instrumentais, por causa da perspectiva de disrupção social que paira de forma ameaçadora sobre muitos lugares problemáticos do nosso planeta;
\end{abstract}

b) Ambiental, com as suas duas dimensões (os sistemas de sustentação da vida como provedores de recursos e como "recipientes" para a disposição de resíduos);

c) Territorial, relacionado à distribuição espacial dos recursos, das populações e das atividades;

d) Econômico, sendo a viabilidade econômica a conditio sine qua non para que as coisas aconteçam;

e) Político, a governança democrática é um valor fundando e um instrumento necessário para fazer as coisas acontecerem; a liberdade faz toda a diferença (SACHS, 2008, p. 15).

Os requisitos supra, demonstram uma necessária mudança de paradigma em relação ao modo pelo qual ocorre a exploração econômica dos bens em relação à sociedade para que os objetivos que derivam do conceito de desenvolvimento sustentável e que estão relacionados com o processo de crescimento econômico e tecnológico permitam a conservação dos recursos naturais e estabeleçam o uso racionado destes nas atividades produtivas, inserindo assim, definitivamente a empresa como parte integrante deste sistema, responsabilizando-a efetivamente pelas externalidades ambientais que gera.

Entre os objetivos do desenvolvimento sustentável estão: - crescimento renovável; mudança de qualidade do crescimento; - satisfação das necessidades essenciais por emprego, água, energia, alimento e saneamento básico; - garantia de um nível sustentável da população; - conservação e proteção da base de recursos; - reorientação da tecnologia e do gerenciamento de risco; - reorientação das relações econômicas internacionais (BARBOSA, 2008).

A empresa hoje, aliada a políticas públicas eficientes e norteadoras, desempenha papel indispensável no tema desenvolvimento sustentável. Assim, deve fazer parte da estratégia do desenvolvimento empresarial urbano a busca por alternativas sustentáveis e que esquadrinhem qualidade de vida para a dinâmica urbana, consolidando uma referência para o processo de planejamento urbano alicerçado no conceito de sustentabilidade ambiental.

Neste sentido, em sua obra Ferreira afirma que

[...] o padrão de produção e consumo que caracteriza o atual estilo de desenvolvimento tende a consolidar-se no espaço das cidades e estas se tornam cada vez mais o foco principal na definição de estratégias e políticas de desenvolvimento (FERREIRA, 1998, p. 32).

Outros autores que se debruçam sobre o tema da sustentabilidade alertam para as mesmas necessidades, neste sentido apresenta-se que: - a eficiência, antagônica ao desperdício como base material do desenvolvimento, com reflexos da racionalidade econômica sobre o

[...] espaço não mercantil planetário; a escala, determinante de limites quantitativos para o crescimento econômico e suas respectivas pressões sobre os recursos ambientais; - a equidade, articuladora analítica entre princípios de justiça e ecologia; -a autossuficiência, desvinculadora de economias nacionais e sociedades tradicionais dos fluxos de mercado mundial, como estratégia apropriada para a capacidade de auto regulação comunitária das condições de reprodução da base material do desenvolvimento; a ética, evidenciadora das interações da base material do desenvolvimento com as condições de continuidade da vida do planeta. (ACSELRAD; LEROY, 1999, p. 39). 
Pode se verificar que o discurso sobre a necessidade de se atentar para o desenvolvimento sustentável é recorrente entre os doutrinadores, resgatando com este discurso que deve ser implantado na prática, a visão ética que a economia perdeu quando se focou somente nos lucros, sem se preocupar com os danos ambientais, passando a propiciar um desenvolvimento econômico de longo prazo e eficiente.

O Brasil, no cenário ambiental, tardou em mostrar preocupação com a necessidade de se educar a população, principalmente aquela que se dedica à área empresarial, no sentido de preservação do meio ambiente, como única forma de perpetuar a sobrevivência, sendo que, ainda hoje se apresenta carente de educação e consciência sobre preservação ambiental.

No entanto, é preciso se impulsionar por meio de políticas públicas ambientais eficientes esse novo empresariado, que seja consciente das suas responsabilidades pelas externalidades que gera ao meio ambiente, criando uma nova equação que permita com ações equilibradas entre desenvolvimento empresarial, lucro, meio ambiente saudável edesenvolvimento social, implementar de modo escorreito as exigências do modelo econômico descrito na Constituição Federal, notadamente o artigo 170, fazendo com que a ordem econômica brasileira atinja o pleno desenvolvimento e a pretendida justiça social. Assim, no tópico a seguir discute-se a questão das externalidades e a responsabilidade social das empresas.

\section{A EMPRESA - RESPONSABILIDADE SOCIAL E EXTERNALIDADES}

Atribuir uma definição para função social da empresa não é tarefa fácil. Ocorre muita confusão com relação ao tema e não são raros os casos em que se confunde a responsabilidade social com "ação social". Estes termos, no entanto, são distintos e a ação social está relacionada a projetos sociais ou ações sociais, como doações que a empresa, assim como o indivíduo, pode fazer, em benefício de algum projeto social ou grupo de pessoas necessitadas. Outrossim, a responsabilidade social da empresa está diretamente relacionada a ações efetivas da empresa com um grupo maior de pessoas e bens, que engloba consumidores, fornecedores, empregados, meio ambiente, com a finalidade de permitir o desenvolvimento econômico, o crescimento da empresa, sem deixar de se responsabilizar pelo meio ambiente e as desigualdades sociais.

Neste sentido, Oliveira (2008) explicita em sua obra o modelo de empresa socialmente responsável estabelecido por Davis e Blomstron:

\footnotetext{
Por exemplo, um dos modelos mais simples é o proposto por Davis e Blomstrom. Nele, as responsabilidades se expandem desde um círculo interior que trata de aspectos técnicos e econômicos, para englobar as responsabilidades trabalhistas e ambientais ligadas diretamente às atividades da empresa, até finalmente buscar o engajamento com aspectos fora das atividades da empresa, como pobreza e desigualdades sociais. A empresa e os gestores, à medida que buscam maior responsabilidade socioambiental, teriam, então, de arcar com uma gama crescente de preocupações além daquelas técnico-econômicas (OLIVEIRA, 2008, p. 71).
}

Não há na literatura uma conceituação uníssona sobre o tema da responsabilidade social da empresa e por tal razão o entendimento dele passa por várias vertentes, tais como considerar socialmente responsável a empresa que cumpre todas as determinações legais, consegue atender aos anseios dos grupos com que se relaciona interna e externamente, respeita o meio ambiente e ainda se insere em projetos sociais. Ao que parece, a somatória de todos os elementos indicados é o que define o comportamento de responsabilidade social desejável por parte de uma empresa no atual cenário político e econômico. 
O meio ambiente e sua preservação devem ser, dentro de todo este contexto, uma grande preocupação a se analisar, isto porque diretamente é afetado pelas atividades tecnológicas e industriais do ser humano e nem sempre ocorre uma análise econômica dos custos que esta intervenção gera, com isso surgem as externalidades negativas.

Deste os primórdios o homem passou a degradar o meio ambiente como mecanismo de produção extrativa para atender a suas necessidades vitais de sobrevivência e crescimento, sem inserir nos custos operacionais da exploração de recursos naturais, até mesmo porque, de início acreditava que tais recursos seriam infinita e automaticamente repostos; atualmente, tal conceito não mais se sustenta e, no entanto, a humanidade continua explorando o meio ambiente e o faz para garantir prazeres e obter bens supérfluos, que em boa parte dos casos não guardam relação com necessidades e nem são indispensáveis à sobrevivência.

Se nos primórdios da humanidade o meio ambiente servia para mantença da vida humana, hoje é preciso reconhecer que a preservação dele é ponto fundamental a evitar que ocorra a extinção da vida na Terra. Hoje os meios de produção devem voltar seus olhares para o desenvolvimento sustentável e a empresa desempenha importante função para garantir o direito à vida com dignidade, cumprindo assim, o preceito do princípio da dignidade da pessoa humana estabelecido na Carta Constitucional, em seu artigo 1으. III. (GODOY, 2017, p. 27-28).

A empresa não pode mais atuar sem observar os preceitos constitucionais que lhe são impostos pela nova ordem econômica, insertos no artigo 170 da Constituição, e nem mesmo deixar de priorizar o princípio da dignidade da pessoa humana; sendo que somente uma atuação empresarial que se coadune com a função social da empresa na busca do desenvolvimento sustentável é capaz de atingir esses objetivos.

Por certo exerce função social a empresa que dispõe dos recursos naturais de forma adequada e reduz ao mínimo o impacto de suas atividades no meio ambiente; para isso ela deve estar atenta às externalidades que ocasiona e quando estas forem negativas, deve atuar para reparar os danos e recuperar o meio ambiente. A gestão das empresas atualmente não pode mais ocorrer, sem levar em consideração o cumprimento da responsabilidade socioambiental que ela possui frente ao desafio de se preservar o meio ambiente para as futuras gerações, o que passa necessariamente pelo controle das externalidades negativas de forma eficiente.

A gestão responsável de uma empresa, do ponto de vista ambiental, é definida pela relação ética e transparente que ela mantém com todos os públicos com os quais se relaciona, e pelo estabelecimento de metas empresariais compatíveis com o desenvolvimento sustentável da sociedade, preservando recursos ambientais, recuperando os lesados e investindo em tecnologias para reduzir impactos a bens ambientais.

Não se pode negligenciar também a noção da realidade social e a necessidade de se atingir o desenvolvimento sustentável, inclusive reduzindo desigualdades sociais; entretanto, este é um processo de aprendizagem social de longo prazo, que deve ser orientado e direcionado por políticas públicas eficientes que tenham por escopo um plano de desenvolvimento nacional.

Assim, não se pode exigir somente das empresas que desempenhem sozinha este papel, mas ele demanda uma pluralidade de atores sociais e ainda é necessário se considerar que interesses outros, presentes na sociedade, são colocados como um entrave em matéria de políticas públicas para o desenvolvimento sustentável (BEZERRA; BURSZTYN, 200o, p. 45).

Em todo este complexo contexto, o lucro é e continuará sendo um dos pilares de sustentação para as empresas se mantenham no mercado. No entanto, ao se observar os indicadores de uma boa gestão empresarial contábil, o que se pode perceber é que as empresas que adotaram a cultura da ecoeficiência demonstram a perfeita compatibilidade entre 
lucratividade e sustentabilidade e manejam de forma responsável suas externalidades. Criar mecanismos para reaproveitar matérias-primas, promover o reuso da água e racionalizar energia, reduz o impacto do processo produtivo no meio ambiente e aumenta a competitividade do produto no mercado, tanto do ponto de vista tangível como do intangível. Inicia-se, inclusive, um processo de conscientização do consumidor quanto à preferência a produtos ecologicamente responsáveis.

Carvalhosa (1997), ao comentar a Lei das Sociedades Anônimas, acenava com a necessidade da empresa aliar como seus objetivos, a exploração econômica e a preservação do meio ambiente, incluindo assim, como uma das funções sociais da empresa, o dever de preservar o meio ambiente, bem antes do surgimento oficial do conceito de desenvolvimento sustentável ou da nova ordem constitucional que recepcionou o meio ambiente como um direito indissociável ao ser humano

\footnotetext{
E ainda mais atual é a preocupação com os interesses de preservação ecológica, urbana e ambiental da comunidade em que a empresa atua. O compromisso com a preservação da natureza transcende, outrossim, os aspectos meramente comunitários, para se colocar num plano universal. A produção de elementos nocivos não só ao homem, como também à fauna e a flora, constitui dano de igual importância. (CARVALHOSA, 1997, p. 238)
}

Verifica-se que passados 20 anos deste precioso conceito, a empresa ainda está aprendendo a se enquadrar no conceito de desenvolvimento sustentável, que vem acontecendo como uma revolução silenciosa.

Como ocorre em qualquer processo revolucionário, há uma ruptura de ações e de conceitos; o lucro, sob a ótica da sustentabilidade, deve ser objetivado de uma maneira mais ampla e a longo prazo. Já não se justifica mais a obtenção de lucro a qualquer preço. Empresas que mantiverem essa forma de administração, ignorando as externalidades ambientais acabarão por não se sustentar no mercado e virão a falir por teimar em não reconhecer que a mantença dos negócios depende do respeito ao meio ambiente e seus recursos.

Neste momento, é importante apresentar o conceito descrito por Sachs (1993) no que se refere a meio ambiente e sustentabilidade como:

\footnotetext{
Sustentabilidade ecológica - refere-se à base física do processo de crescimento e tem como objetivo a manutenção de estoques dos recursos naturais, incorporados as atividades produtivas. Sustentabilidade ambiental - refere-se à manutenção da capacidade de sustentação dos ecossistemas, o que implica a capacidade de absorção e recomposição dos ecossistemas em face das agressões antrópicas. Sustentabilidade social - refere-se ao desenvolvimento e tem por objetivo a melhoria da qualidade de vida da população. Para o caso de países com problemas de desigualdade e de inclusão social, implica a adoção de políticas distributivas e a universalização de atendimento a questões como saúde, educação, habitação e seguridade social. Sustentabilidade política - refere-se ao processo de construção da cidadania para garantir a incorporação plena dos indivíduos ao processo de desenvolvimento. Sustentabilidade econômica - refere-se a uma gestão eficiente dos recursos em geral e caracteriza-se pela regularidade de fluxos do investimento público e privado. Implica a avaliação da eficiência por processos macro sociais (SACHS, 1993, p. 27).
}

A literatura reconhece que se está diante de um grande desafio quando se fala em desenvolvimento sustentável e que ele é um norte para o século XXI, diante da era da globalização, que não pode ser esquecida neste processo. Neste sentido, Veiga (2003) afirma que o conceito de desenvolvimento sustentável é uma utopia para o século XXI, apesar de 
defender a necessidade de se buscar um novo paradigma científico capaz de substituir os paradigmas do "globalismo".

O desenvolvimento sustentável deve ser um resultado da equação de desenvolvimento social, econômico e da preservação ambiental, conjuntamente, o que demonstra que a empresa, neste contexto, não pode mais ser observada somente pelo interesse econômico de seus sócios no lucro, mas deve observar as externalidades ambientais negativas e equilibrar este processo, internalizando e equilibrando essa equação com o lucro pretendido.

Importante análise é feita por Tombs e Whyte (2016) ao observarem que as corporações agem de forma a gerarem danos sociais, cometem crimes contra consumidores, contra trabalhadores e contra o meio ambiente:

\begin{abstract}
La historia de la corporación es la historia de sus crímenes, uma historia muy anterior a la industria del automóvil moderno. Es, de hecho, más antigua que cualquiera de las industrias modernas. La corporación fue concebida como una 'persona' idealizada, con su propia identidad, con capacidad de poseer propiedades y reclamar 'derechos' hasta entonces reservados a algunas personas físicas. Es este mismo proceso el que permite atribuirle también ciertas formas de falsa racionalidad —incluida la capacidad de comportarse de modo 'responsableı y 'ético' (TOMBS; WHYTE; 2016, p. 18).
\end{abstract}

"Assim, o avanço do neoliberalismo permite um avanço no abuso do poder corporativo, para mudar o curso se faz necessário frear o poder político e econômico das corporações" (TOMBS; WHYTE, 2016, p. 55-57).

Neste sentido, é de fundamental importância discutir a regulação destas atividades empresariais e das externalidades.

\title{
5 REGULAÇÃO DAS EXTERNALIDADES
}

Como descrito anteriormente, as externalidades indicam que o agente produtor não considerou ao produzir o custo de poluir o meio ambiente, o que faz com que o agente polua inadvertidamente e transfira para o meio ambiente e a sociedade o custo ambiental de sua produção. Com as falhas de mercado, a busca pelo interesse individual fundada no mercado tende a piorar a situação da sociedade, isto é, o mercado econômico se mostra ineficiente.

A externalidade negativa em matéria ambiental implica maior poluição devido à subestimação de custos e, em consequência, viabiliza a permanência no setor econômico de agentes de produção inviáveis e que demonstram despreocupação com a responsabilidade ambiental.

A falha de mercado, em casos semelhantes, é supedâneo para o interesse do Estado intervir criando mecanismos de correção da externalidade, defendendo, assim, o bem estar social; geralmente, o faz por meio da regulação, sendo comum a criação de instrumentos como a incidência de imposto ou mesmo a fixação de limites polutivos, para tentar conter este processo danoso, utilizando-se da regulação para tanto.

Teoria da Regulação, brevemente se explicando, se consubstancia em uma tentativa de obter respostas para algumas das questões centrais do pensamento social e econômico, quais sejam: a coesão social, crise e crescimento econômico. Os regulacionistas que são os estudiosos desta doutrina, entendem que o estudo de tais questões passa pelo conceito de modo de regulação, que possibilita estabelecer a mediação entre a macroestrutura do regime de acumulação e os comportamentos dos indivíduos.

No contexto proposto, a Teoria da Regulação propõe mais alguns conceitos básicos, com a finalidade de ser confrontada com o mundo real. 
Inicialmente, tem-se que a definição de regulação conduz diretamente ao conceito de modo de regulação, o qual pode ser compreendido como sendo o conjunto de procedimentos e de comportamentos individuais e coletivos, que possuem, de acordo com Nascimento (1993) três premissas básicas: i) reproduzir as relações sociais fundamentais através de um conjunto de formas institucionais determinadas; ii) sustentar e dirigir o regime de acumulação, conceito este que será definido logo a seguir; iii) assegurar a compatibilidade dinâmica de um conjunto de decisões descentralizadas.

Desta forma, para a Escola da Regulação, o conjunção de procedimentos e comportamentos efetivos gerados a partir do modo de regulação possibilita o ajuste entre as decisões dos agentes econômicos, múltiplos e descentralizados, cuja racionalidade é limitada.

No que concerne ao neoclassicismo, o que se verifica é a substituição de um equilíbrio estático, por uma análise dos processos dinâmicos de solução dos desequilíbrios que a acumulação gera permanentemente.

Por fim, a racionalidade dos agentes às informações e a capacidade dos mesmos em adotar uma racionalidade localizada é restringida e os mercados são inseridos em uma série de dispositivos institucionais que socializam tanto a informação quanto os comportamentos.

Partindo-se desta última premissa, abre-se a possibilidade de que o modo de regulação diferencie significativamente tendo em vista a época e o lugar em que seja aplicado, não refletindo apenas a projeção de um mesmo modelo de equilíbrio geral, uma vez que as imperfeições são introduzidas pelas "especificidades nacionais" (PETIT; AMABLE, 1998, p. 62).

Assim, na esfera da Teoria da Regulação, períodos de crescimento são compreendidos como etapas marcadas por regimes e acumulação que permitem a concordância entre as normas de produção e consumo, propiciando acumulação de capital.

Entretanto, em situações que o regime de acumulação não se sustenta mais sozinho, são necessárias normas institucionalizadas que o assegurem. Neste momento a articulação de tais formas parciais de regulação, tais como a relação salarial, a gestão da moeda, a intervenção do estado, entre outras, são os mecanismos que possibilitam a permanência e a continuidade do regime de acumulação.

\begin{abstract}
A teoria da regulação, sob a ótica estatal, compreende o objetivo de estudar a atividade econômica e como se dá a intervenção do Estado, seja pelo serviço público ou pelo exercício do poder de polícia. O Estado regula a atividade seja impondo preços e quantidades produzidas, como estabelecendo regras (SALOMÃO FILHO, 2001, p. 21).
\end{abstract}

Na visão do referido autor a regulação pressupõe uma redução da intervenção direta do Estado na economia. Na escola neoclássica a regulação serviria como substituta do mercado, como discutido anteriormente, para Coase (1960), isto deveria ocorrer no mercado, havendo a participação do Estado quando o mesmo não conseguisse uma regulação bilateral.

Sob o enfoque adotado no presente estudo a regulação, qual seja, a regulação estatal para as falhas de mercado, percebe-se que ela deve atuar como um instrumento eficiente a permitir que se mantenha a livre concorrência de produtos e serviços, focando um conjunto de análises que tenham por objetivo evitar as falhas de mercado e atender o interesse público, sem perder de vista ao bens maiores que devem ser protegidos neste contexto.

No mesmo sentido as palavras de Bagnoli (2008, p. 83) sobre a regulação:

As acepções do termo regulação referem-se às normas de organização da atividade econômica pelo Estado, tanto pela concessão de serviços públicos quanto pelo poder de 
polícia. Especificamente no campo econômico, diz respeito à redução da intervenção direta do Estado e à concentração econômica.

Regular externalidades tem como objetivo internalizar e reduzir o impacto não precificado, isto porque a premissa de que o preço do produto não reflete seu verdadeiro custo para a sociedade, ultrapassa questões monetárias e atinge o meio ambiente e bem estar social, demonstrando a necessidade da regulação.

A regulação pode tanto se destinar as externalidades positivas, gerando incentivos ao empreendedor, como pode se destinar a regular as externalidades negativas, visando eliminar danos sociais e ambientais, evitando que empresas se beneficiem e tenham lucros indevidos, por trabalharam irregularmente, sem respeito ambiental.

Krugman e Wells pontuam os mecanismos de governança que devem observar a regulação das externalidades

(i) ao analisar os efeitos colaterais - as externalidades causadas aos terceiros -o governo pode impor um controle direto levando o mercado rumo à quantidade correta de efeitos colaterais de maneira direta;

(ii) ao analisar a atividade original, e não seus efeitos, o governo pode aplicar políticas que afetam a atividade original, alcançando indiretamente a quantidade correta de efeitos colaterais (KRUGMAN; WELLS, 2007, p. 430).

As politicas públicas devem levar as empresas a focar sua produção tendo em vista o interesse social e não apenas o interesse dos sócios ou acionistas. O caminho para se atingir o que se denomina por ótimo social, em que há externalidades, é fazer com que as empresas foquem no custo marginal social e não no custo marginal privado somente (COOTER, 2010).

A regulamentação das atividades empresariais, por parte do Estado, é a melhor forma para delinear estas situações, já que com ela surge uma série de regramentos jurídicos provenientes dos órgãos governamentais competentes e que interferem no modo de produção e, portanto, na eficiência das empresas, afetando o mercado; ou seja, mudando paradigmas operacionais.

No Brasil, com o estabelecimento do Estado neoliberal e do processo de globalização, as privatizações e concessões de serviços públicos, durante a década de 90, geraram uma diminuição da atuação estatal, fortalecendo a iniciativa privada; houve uma grande transformação no modelo de administração pública e surgiram as denominadas agências reguladoras, trazidas a nosso texto Constitucional por meio das emendas número 8 e 9, de 1995 . São elas autarquias especiais vinculadas à administração pública indireta, com a finalidade de regular setores de mercado para garantia de direitos e do próprio funcionamento do mercado e atuam nesta regulação de natureza ambiental. Estes órgãos detém autonomia funcional e poder regulamentar sobre o setor de sua competência.

\footnotetext{
Quando se trata de regulação, Salomão Filho alerta para a necessidade de se reconhecer que convivem aspectos econômicos e sociais, sendo também importante se perceber que, por vezes, um prepondera sobre o outro, dependendo da natureza do setor regulado (SALOMÃO FILHO, 2001. p. 21).
}

No que tange à atividades econômicas que tenham ingerência sobre o meio ambiente a regulamentação deve servir de defesa do meio ambiente; e, aqui, prepondera o interesse social.

A sociedade brasileira vem, gradativamente, evoluindo de uma visão da degradação ambiental como um mal necessário, para, com o conhecimento da finitude de recursos naturais, 
reconhecer que o uso inadequado do meio ambiente é sempre prejudicial à manutenção da vida humana.

Neste contexto, se vislumbra que prepondera o interesse social da regulação deste setor e a sociedade atua como importante fator a ser considerado, paralelamente aos interesses das empresas, na pressão política sobre as instituições legisladoras para que regulem o mercado e contenham externalidades negativas sobre o meio ambiente.

Por derradeiro, no que tange à regulação, é preciso de toda forma evitar o denominado colapso regulatório, que ocorre quando a regulamentação proposta se mostra ineficiente para resolver os problemas para a qual se destina, ou também em casos em que acaba por gerar problemas não intencionais na eficiência dos agentes.

\begin{abstract}
Evitar que ocorra o colapso regulatório exige que o agente regulador tenha independência, recursos materiais para atuar e indispensável qualificação técnica. Assim, nos países menos desenvolvidos a regulamentação contrária aos interesses de grupos políticos importantes tem grande chance de incorrer no colapso regulatório, colocando em dúvidas a garantia ao direito e efetividade do procedimento. (SANTANA, 1995, p. 85).
\end{abstract}

\title{
6 CONSIDERAÇÕES FINAIS
}

De todo o exposto percebe-se que a visão de desenvolvimento econômico de uma empresa focada somente no lucro do empreendedor mudou em razão da necessidade premente de se resguardar os recursos ambientais finitos.

As atividades empresariais não podem mais se subsumir à exploração de recursos naturais sem analisar as externalidades negativas que este comportamento gera e que afetam o meio ambiente e a sociedades; assim não basta mais um viés somente de crescimento econômico.

O lucro, objetivo que impulsiona a economia, é o motivo fundamental que leva à criação de empresas, deve ser analisado com as devidas reservas que todo o contexto sócio-políticoambiental exige.

A visão da prática do lucro sem inserir custos ambientais, atualmente, não satisfaz as necessidades e custos sociais de impactação e escassez de recursos ambientais. Obter lucros, sem internalizar os custos das externalidades ambientais negativas, é transferir para a sociedade um alto preço de má qualidade de vida e mitigação do desenvolvimento social; fórmula esta que não se adequa à realidade atual.

A empresa hoje é vista em âmbito mais amplo, tendo-se em consideração o modo como ela interage no mercado, com seus funcionários, consumidores, comunidade onde se instala e o modo como trata o meio ambiente e o impacto que nele gera.

A intervenção do Estado regulando as externalidades geradas pelos impactos ambientais, por meio de políticas públicas legislativas que determinam responsabilidades, exerce papel fundamental neste cenário.

Assim, se por um lado a Constituição Federal prevê a livre iniciativa, de outra sorte determina que esta deva cumprir a função de permitir o desenvolvimento econômico e social, reduzindo desigualdades e preservando o meio ambiente para as atuais e futuras gerações.

Em todo este arcabouço de normas, a empresa deve se inserir e cumprir também sua função social ambiental, não só promovendo lucros a seus sócios, mas atuando diretamente na redução de externalidades negativas ao meio ambiente, promovendo a sua preservação. 
O desafio de criar uma nova ordem econômica baseada na livre indicativa, mas com um Estado Mínimo, é árdua tarefa a se concretizar à empresa neste contexto, cabe o papel de adequar seus interesses de obtenção de lucro às necessidades sociais do mercado trabalhador, consumidor e, fundamentalmente a necessidade de preservação e recuperação ambiental, já que sem o meio ambiente, não haverá futuro.

A visão ampliada da juridicidade ambiental é fator determinante diante do Estado regulador, porque permite a ele conter as discrepâncias da aplicação do princípio da livre iniciativa em face ao meio ambiente.

Deve-se destacar também outro benefício que é a proeminência e preeminência das normas de caráter ambiental, que vinculam o ordenamento jurídico e servem para orientar as decisões neste setor. Com isso, a regulação dos preceitos legais, tomando-se por base a juridicidade ambiental, permite que as agências reguladoras, criadas com o fito de regular setores de mercado garantindo seu próprio funcionamento, atuem no sentido de preservação ambiental, estabelecendo mecanismos para internalizar as externalidades negativas geradas, com isso concretizando o direito ao meio ambiente equilibrado, previsto no art. 225 e 170 da Constituição Federal.

É necessário que os princípios ecológicos sejam observados como alicerces para a formulação de políticas econômicas eficientes, integrando a participação de governos com a sociedade, no afã de se criar meios de produção mais eficientes. Exige-se um novo olhar sobre o sistema econômico para que ele considere efetivamente as externalidades causadas nas atividades de produção e consumo sobre o meio ambiente.

Em um mundo em que é imperioso se reconhecer que os recursos naturais são finitos, a integração do desenvolvimento econômico com a devida análise das externalidades negativas que a atividade empresarial pode ocasionar ao meio ambiente é fulcral a permitir que a empresa desenvolva suas atividades observando a sustentabilidade ambiental.

\section{REFERÊNCIAS}

ACSELRAD, Henri e LEROY, Jean P. Novas premissas da sustentabilidade democrática. Revista Brasileira de Estudos Urbanos e Regionais, v. 1, 1999. Disponível em: <http://www. educacaoambiental.pro.br/victor/biblioteca/AcselradLeroyNovasPremissas.pdf $>$ Acesso em: 18 out. 2017.

AMABLE, B., PETIT, P. Ajustamento estrutural e política industrial: uma abordagem regulacionista. In: Regulação Econômica e Globalização (org.), Campinas: UNICAMP, 1998.

BAGNOLI, Vicente. Direito Econômico. 3. ed. São Paulo: Atlas, 2008.

BARBOSA, Gisele Silva. O desafio do desenvolvimento sustentável. 4. ed. v. 1. n. 4. Revista Visões. Disponível em: <http://www.fsma.edu.br/visoes/edo4/4ed_O_Desafio_Do_ Desenvolvimento_Sustentavel_Gisele.pdf>. Acesso em: 08 dez. 2017.

BEZERRA, M. C. L.; BURSZTYN, M. (coord.). Ciência e Tecnologia para o desenvolvimento sustentável. Brasília: Ministério do Meio Ambiente e dos Recursos Naturais Renováveis: Consórcio CDS/ UNB/ Abipti, 2000. 
BRASIL. Constituição (1988) Poder Executivo. Emenda no 91 de 2016. Diário Oficial (da) República Federativa do Brasil. Disponível em: <http://www.planalto.gov.br/ccivil_03/ constituicao/constituicaocompilado.htm>. Acesso em: 16 dez. 2017.

CARVALHOSA, Modesto. LATORRACA, Nilton. Comentários à lei das sociedades anônimas. v. 3, São Paulo: Saraiva, 1997.

COASE, R. H. The problem of social cost. Journal of law and economics, Chicago, p. 1-44, out. 1960.

COMISSÃO MUNDIAL SOBRE MEIO AMBIENTE E DESENVOLVIMENTO (CMMAD). Nosso futuro comum. Rio de Janeiro: Fundação Getulio Vargas, 1988.

COOTER, Robert; ULEN Thomas. Direito e economia. 5. ed. Porto Alegre: Bookman, 2010.

DERANI, Cristiane. Daniel Antônio de Aquino Neto. Hileia: Revista de Direito Ambiental da Amazônia, ano 5, n. 9. Valoração Econômica dos Bens Ambientais, UEA, 2007.

FERREIRA, Leila da Costa. A questão ambiental: sustentabilidade e políticas públicas no Brasil. São Paulo: Boitempo, 1998.

GODOY, Sandro Marcos. O meio ambiente e a função socioambiental da empresa -. Birigui/SP: Boreal, 2017.

KRUGMAN, Paul, WELLS, Robin. Introdução à economia. Rio de Janeiro: Elsevier, 2007.

MOTTA, Ronaldo Seroa. Manual para valoração econômica de recursos ambientais. Terra Brasilis. Rio de Janeiro. Set. 1997. Disponível em: <http://www.terrabrasilis.org.br/ ecotecadigital/pdf/manual-para-valoracao-economica-de-recursos-ambientais.pdf.> Acesso em: 04 maio 2018.

NASCIMENTO, E. P. Notas a respeito da Escola Francesa de Regulação. In: Revista de Economia Política, v. 13, n. 12, abr.-jun., 1993.

OLIVEIRA, José Antônio Puppim de. Empresas na sociedade: sustentabilidade e responsabilidade social. Rio de Janeiro: Elsevier, 2008.

PADILHA, Norma Sueli. Fundamentos constitucionais do direito ambiental, brasileiro. Rio de Janeiro: Elsevier, 2010.

PAFFARINI, Jacopo; COLOGNESE, Mariângela Matarazzo Fanfa; HAMEL, Eduardo Henrique. A insuficiência da Responsabilidade socioambiental empresarial na perspectiva do desenvolvimento sustentável. Direito e Desenvolvimento. v. 8, n 2, p. 55-75, 2017.

PIGOU, A. C. The economics of welfare. London: Macmilan, 1920. 
ROLIM, Francisco Petrônio de Oliveira; JATOBÁ, Augusto César Maurício de Oliveira; BELO, Manoel Alexandre Cavalcante. O desenvolvimento sustentável e o crescimento econômico: uma aabordagem no âmbito das políticas publicas. Direito e Desenvolvimento. v. 5, n. 2, p. 95-110, 2014.

SACHS, Ignacy. Desenvolvimento: includente, sustentável, sustentado. Rio de Janeiro: Garamond, 2008.

SACHS, Ignacy. Estratégias de Transição para do século XXI - Desenvolvimento e Meio Ambiente. São Paulo: Studio Nobel - Fundação para o desenvolvimento administrativo, 1993.

SALOMÃO FILHO, Calixto. Regulação da Atividade Econômica: Princípios e Fundamentos Jurídicos. São Paulo. Malheiros, 2001.

SANTANA, Edvaldo Alves de. Teoria do agente-principal, regulação e performance da indústria de energia elétrica no Brasil.: ENCONTRO NACIONAL DE ECONOMIA, 23, 1995, Rio de Janeiro Anais... v. 1. Rio de Janeiro: Associação nacional dos cursos de pós-graduação em economia (ANPEC), 1995.

SEN, Amartya. O Desenvolvimento como Liberdade. São Paulo: Companhia das Letras, 2010.

SHUMPETER, Joseph Alois. Teoria do Desenvolvimento Econômico: uma investigação sobre lucros, capital, crédito, juro e o ciclo econômico. São Paulo: Nova Cultural, 1997.

SUNKEL, Osvaldo. Globalização, neoliberalismo e reforma do Estado. In: BRESSER-Pereira, L. C.; WILHEIM, Jorge; SOLA, Lourdes. Sociedade e Estado em transformação. São Paulo: UNESP, 2001. p. 173-195.

TOMBS, Steve; WHYTE, David. La empresa Criminal: Por que las corporaciones deben ser abolidas. Barcelona: Icaria editorial, 2016.

VEIGA, José Eli da. Cidades Imaginárias - o Brasil é menos urbano do que se calcula. Campinas: Unicamp, 2003. 